\section{LA REPLICANTE DE ROSA MONTERO: LA NATURALEZA DEL CUERPO ARTIFICIAL}

\section{ROSA MONTERO `S REPLICANT: THE NATURE OF THE ARTIFICIAL BODY}

RODRIGO PARDO-FERNÁNDEZ ${ }^{1}$

MonteRo, R. (20 I I). Lágrimas en la lluvia. Barcelona: Seix Barral.

Montero, R. (20 I 5). El peso del corazón. Barcelona: Seix Barral.

Montero, R. (2018). Los tiempos del odio. Barcelona: Seix Barral.

La escritora española Rosa Montero ha publicado una trilogía de ciencia ficción: Lágrimas bajo la lluvia (2011), El peso del corazón (2015) y Los tiempos del odio (20 I8). La serie toma como punto de partida el filme de corte

'Universidad Michoacana de San Nicolás de Hidalgo.

Correo electrónico: rodrigo.pardo@umich.mx

REVISTA ESTUDIOS DE GÉNERO, LA VENTANA, NÚM. 52, JULIO-DICIEMBRE DE 2020, PP. 398-402, ISSN I405-9436 E-ISSN: $2448-7724$ ciberpunk Blade Runner (1982) de Ridley Scott (el cual a su vez se inspira en Do Androids Dream of Electric Sheep? de Philip K. Dick, 1968): la protagonista de las novelas, Bruna Husky, es una androide replicante (rep) de bataIla. Si bien su apariencia es humana, cuenta con características especiales, mejoras introducidas para llevar a cabo su trabajo como parte de la milicia. La descripción del personaje literario, desde la vestimenta hasta los cambios que presenta, además de su angustia por la muerte inminente (programada en su código genético), remiten a los personajes de la película. La replicante Bruna Husky se define en la ficción como un anuncio de la otredad, en términos de una sociedad que la tolera pero que, al cabo, la necesita.

Los humanos eran lentos y pesados paquidermos, mientras que los replicantes eran rápidos y desesperados tigres, pensó Bruna Husky, consumida por la impaciencia de tener 


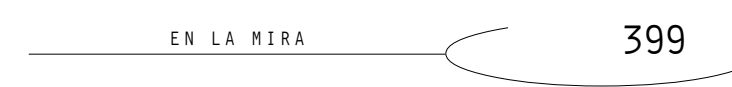

que aguardar en la cola. (Montero,

2018, p. II)

La ciborg de Rosa Montero represen-

ta, en muchos sentidos, el constructo

que nos anuncia en 1984 Donna

Haraway: "Contemporary science

fiction is full of cyborgs -creatures

simultaneously animal and machine,

who populate worlds ambiguously

natural and crafted" (Haraway, 20I6,

p. 6). Bruna Husky, como nosotros en

el contexto de la sociedad contempo-

ránea, no ha tenido alternativa: es una androide de carne sintética, cuyo diseño satisface un conjunto de características especializadas con fecha de término.

Esta obsolescencia programada apunta, de diversos modos, a las condiciones del mundo contemporáneo, donde estamos sujetos a la pérdida de información, software o hardware, que queda en desuso sin remedio, con la condicionante impuesta de adquirir otro soporte. Sin embargo, la enfer- medad terminal que sufre todo replicante en las historias de Montero anuncia la imposibilidad de perpetuar la vida más allá de un periodo arbitrario o relacionado con el promedio de la vida humana, a pesar de los distintos grados de especialización y complementariedad del ciborg en nuestros días (todo lo que tomamos, cambiamos en nuestro cuerpo, consumimos para evitar envejecer o morir).

La obsesión de todo personaje de novela es su pervivencia. En la mayor parte de los casos, sin embargo, esta no se manifiesta de manera explícita, porque se percibe la muerte como algo que les pasa a otros. El cuerpo es perenne, pero negamos constantemente esta certeza; entre otros modos, a partir de la transfiguración del cuerpo como texto. Sin embargo, en la novela la obsesión con el tiempo que se pierde es evidente: no hay escape, la historia es la misma una y otra vez: 


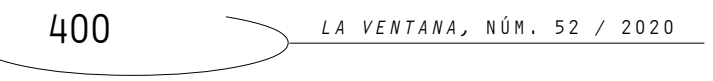

... era posible que los androides tuvieran implantado un chip que les impedía suicidarse, un seguro de los fabricantes para no perder sus caros productos. Se trataba de una idea insoportable, venenosa: si era cierta, pensó Bruna, demostraría la completa falta de respeto, la manipulación a la que los sometían los humanos, al robarles la mayor libertad a la que podía aspirar un ser vivo, que era la de gobernar su propia muerte. Tres años, tres meses y catorce días.

Sintió náuseas.

Se tragó de golpe el resto de la copa. El vino ardió en su estómago y apaciguó poco a poco su malestar. Tres años. Tres meses. Y catorce días. (Montero, 2018, p. 43)

Bruna Husky, como ciborg, lleva en sí misma los límites y parámetros de su fabricación en laboratorio, pero a esto se le suma la posibilidad, que explota por supuesto Montero en distintos pasajes de la trilogía, de sumar elementos que no solo transforman, sino que de-signan, en términos de signo, esto es, la definen frente a otros. Es así que Husky utiliza drogas sintéticas que complementan, enriquecen o tergiversan su experiencia del mundo, y dicho consumo funciona, aunque sea de un modo transitorio, como adiciones, como órganos sensoriales que se suman al cuerpo de la replicante. Esto cobra mayor relevancia cuando el consumo de una droga especial suscita una respuesta acelerada del cuerpo de Bruna Husky, cuyo deseo se ve exponenciado al grado de perder, aunque de manera intencionada, el control sobre su cuerpo.

En unos instantes Bruna empezaría a cruzar la ciudad, navegaría a través de la noche en busca de sexo; de una explosión carnal capaz de vencer a la muerte. La única eternidad posible estaba entre sus piernas. ... El mundo zumbaba alrededor y un la- 


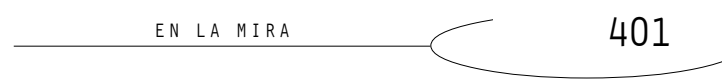

tido de vida estremecía sus venas, su corazón y, sobre todo, el centro de su desnuda flor, justo ahí abajo. (Montero, 20II, pp. I22-123)

Además del consumo de drogas, Bruna Husky transforma su cuerpo mediante elementos que la trasfiguran en otras, en otros. Distintos disfraces apuntan a distintas posibilidades de ser y estar en la realidad; a diferentes modos de ser mirada por los otros, condición sine qua non de la propia transformación del ciborg, dado que el cuerpo es el elemento que en términos sensibles es apreciado por los demás, aparte del propio sujeto, de esta manera las transformaciones de Bruna la configuran en distintas posibilidades como personajes que puede elegir ser de manera transitoria, pero que a su vez, puede abandonar en el momento que así lo decida.

Quizá el elemento que la replicante, en tanto ciborg, asume de manera más plena como identificador, como elección identitaria, lo constituye el tatuaje que cruza todo su cuerpo. Lo que se traduce como una línea de escritura voluntaria, de cuerpo integral:

-Quiero que me tatúes una línea alrededor del cuerpo. Empezando por el cráneo, bajando por la frente, por la mitad de los párpados del ojo izquierdo, la mejilla, el cuello, el pecho, el abdomen, la pierna izquierda, el pie. Y luego subir de igual manera por detrás hasta juntar la raya en la cabeza- explicó la pequeña androide con firmeza. (Montero, 2018, p. 280)

El tatuaje representa una cinta de Moebius, un símbolo del infinito como aspiración de la propia Bruna, pero también de la perpetuidad o permanencia del yo narrativo, y de algún modo, del yo lector. Una línea sin fin que cruza el cuerpo, lo engloba, lo encierra pero a su vez explicita el deseo de sobrevivir. En el caso de la replicante dicho deseo se enfrenta a un término que 
$402 \bigcirc$ La ventana, núm. 52/2020

contrasta con la humanidad: "Los humanos, con sus existencias larguísimas y sus vejeces interminables ..." (Montero, 20।8, p. II).

Es significativo que el dibujo cruce el cuerpo y esté escrito de manera definitiva sobre la piel. El cuerpo representa nuestro estar-en-el-mundo, el tatuaje, una manifestación asumida por la cultura pop de intervención sobre la carne, nuestra presencia física de cara en principio a nosotros mismos, pero aludiendo e interpelando también a los otros que nos miran y nos definen. La replicante de Rosa Montero, su alter ego Bruna Husky, es el espejo deformado de la ficción que hace un ejercicio hiperbólico de nuestro presente ciborg, donde la naturaleza del cuerpo es su artificialidad, su configuración social (condiciones que subyacen y en las cuales nos desarrollamos) y las intervenciones voluntarias a las que lo sometemos.

\section{Bibliografía}

Dick, P. K. (1968). Do Androids Dream of Electric Sheep?. New York: Doubleday.

Haraway, D. (20I6). A Cyborg Manifesto. Science, Technology, and Socialist-feminism in the late Twentieth Century, Minnesota: University of Minnesota Press. ScotT, R. (dir.) (1 982). Blade Runner. Estados Unidos, Reino Unido, Hong Kong, Ladd CompanyShaw Brothers-Warner Bros. 